\title{
Decompressive Craniectomy in Traumatic Brain Injury: Factors Influencing Prognosis and Outcome
}

\author{
Seyed Reza Bagheri 1, Ehsan Alimohammadi 2*, Hamidreza Saeidi ${ }^{3}$, Reza Fatahian ${ }^{1}$, \\ Pezhman Soleimani ${ }^{1}$, Parandoosh Sepehri ${ }^{1}$, Alireza Abdi ${ }^{4}, 0$ mid Beiki 5
}

${ }^{1}$ Assistant Professor of Neurosurgery, Kermanshah University of Medical Sciences, Kermanshah, Iran
${ }^{2}$ Resident of Neurosurgery, Kermanshah University of Medical Sciences, Kermanshah, Iran
${ }^{3}$ Associate Professor of Neurosurgery, Kermanshah University of Medical Sciences, Kermanshah, Iran
${ }^{4}$ Assistant Professor of Nursing, Kermanshah University of Medical Sciences, Kermanshah, Iran
${ }^{5}$ Associate Professor of Epidemiology, Department of Clinical Neuroscience, Karolinska Institute, Stockholm, Sweden.
Kermanshah University of Medical Sciences, Kermanshah, Iran

* Corresponding Author Address: Department of Neurosurgery, Kermanshah University Of Medical Sciences, Kermanshah, Iran. Tel: +989181262143. Email: hafez125@gmail.com

\section{Abstract}

Background and Aim: Decompressive craniectomy can be life-saving for patients with severe traumatic brain injury, but many questions about its ideal application, indications, timing, technique, and even the definition of success of decompressive craniectomy remains unclear. The aim of this study was to assess the factors associated with prognosis and outcome of patients with traumatic brain injury who had undergone a rapid decompressive craniectomy.

Methods and Materials/Patients: We investigated 61 patients, who had undergone rapid decompressive craniectomy. The effect of variables including demographic features of patients, primary level of consciousness, pupil size and reactivity, and midline shift in patients' brain CT scan on outcome of patients were assessed.

Results: 61 patients (36 males and 25 females) underwent rapid surgical decompressive craniectomy within $4.5 \pm 2$ hours after trauma. Mean age of patients was $36.09 \pm 15.89$ years old (range: 16 to 68 years). Of 61 patients, $33(54.1 \%)$ had favorable and $28(45.9 \%)$ had unfavorable outcome. Patients with following conditions had significantly worse outcome; age older than 60 years, bilateral non-reactive mydriasis, critical head injury $(\mathrm{GCS}<5)$, midline shift more than 10 millimeters in their brain CT scan. GCS and age could predict the outcome of surgery more significantly than other variables, so that higher age predicted unfavorable outcome with 1.13 times, and in GCS $<5$ the probability of unfavorable outcome is about 192 times. Patients with midline shift more than $10 \mathrm{~mm}$ are 6.15 times more likely to have risk of unfavorable outcome than those with midline shift less than $10 \mathrm{~mm}$.

Conclusion: In this study, we found that age more than 60 years and GCS less than five were associated with poor outcome. Patients with these conditions could not benefit much from early decompressive craniectomy.

Keywords: Decompressive Craniectomy; Glasgow Outcome Scale; Glasgow Coma Scale

Please cite this paper as: Bagheri SR, Alimohammadi E, Saeidi H, Fatahian R, Soleimani P, Sepehri P, Abdi A, Beiki O. Decompressive Craniectomy in Traumatic Brain Injury: Factors Influencing Prognosis and Outcome. Iran J Neurosurg. 2017;3(1):21-26

\section{Introduction}

Traumatic brain injury (TBI) which is a significant cause of morbidity and mortality is associated with high economic costs to the healthcare system [1-3].

The brain damage induced by TBI is divided into primary and secondary injuries. Primary injury results from direct traumatic impact. Secondary injury occurs as a result of a cascade of biochemical events that induce brain edema and increased intracranial pressure (ICP) [2-3].

The important point to save patients with severe TBI is prevention and/or decreasing secondary brain damages by medical and surgical therapies $[3,5]$.

Medical treatment for brain edema and elevated ICP consists of analgesia, sedation, 
head elevation, cerebrospinal fluid drainage via a ventricular catheter, and optimization of ventilation to prevent cerebral vasodilation secondary to hypercarbia, administration of hyperosmolar solutions such as manitol, moderate hypothermia, and barbiturate coma $[9,10,12,14-16]$.

In about $10-15 \%$ of patients with TBI and elevated ICP, maximal medical treatment failed $[17,18]$. In these patients that are refractory to medical therapy, decompressive craniectomy (DC) could be performed [6,7]. DC could be life-saving for these patients, according to a study conducted in 2009 by Rubiano et al. Prognosis and outcome in DC group were better than those in the control group that received only medical treatment. DC induced decrease in mortality [13]. Yet many questions including ideal application, indications, timing, technique, and even the definition of success of DC remained unclear. In a meta-analysis conducted in 2012 by Bor-Seng-Shu et al., ICP after surgery in patients undergoing DC was dramatically lower than preoperative values, and cerebral perfusion pressure (CPP) was significantly higher than preoperative values. According to this study, more studies are needed to determine the patients who may benefit from DC [11]. The aim of this study was to assess the factors associated with prognosis and survival of patients with TBI who had undergone a rapid DC.

\section{Methods and Materials/Patients}

This is a prospective study done on patients with severe TBI that were candidate for DC according to their initial brain CT scan findings during April 2011 to April 2014. Patients with severe TBI and CT scan findings demonstrating high ICP and midline shift more than five mm underwent early DC (surgery during the first six hours of trauma). Outcome of patients was assessed with the use of the Glasgow Outcome Scale (GOS) at six months during referral of patients to our clinic or contacting with patient or a caregiver by telephone and completing the questionnaire. The correlation of variables including age, sex, primary GCS, pupils' size and reactivity and midline shift in patients' initial brain CT scan with patients' outcome were assessed. The GOS is a global outcome scale assessing functional independence, work, social and leisure activities, and personal relationships. Its five outcome categories are as follows: death, vegetative state (unability to obey commands), severe disability (dependence on others for care), moderate disability (independence at home and outside home but with some physical or mental disability), good recovery (ability to resume normal activities with some injuryrelated problems). GOS had dichotomies. A GOS of $\leq 3$ was classified as an unfavorable outcome; otherwise, a favorable outcome was assumed. Patients older than 70 and younger than 15 years of age and those with mass lesions greater than $25 \mathrm{cc}$ in their brain CT scan were excluded.

\section{Statistical Analysis}

All numerical data are given as mean \pm standard deviation (SD). Categorical data were evaluated using the $\chi^{2}$ test. A p-value $\leq 0.05$ was considered to be significant. Binary logistic regression analysis was used to analyze the prognostic impact of pretreatment factors on GOS.

Outcome (favorable and unfavorable) was considered as dependent variable and others including age, GCS, pupil's size and midline shift were independent (predictor) variables. For categorization of pupil's size and GCS, "midsize" and "GCS $>8$ " were considered as the reference category, respectively. GOS had dichotomies. A GOS of $\leq 3$ was classified as an unfavorable outcome; otherwise, a favorable outcome was assumed. The model was fit because the Hosmer and Lemeshow test was not significant $(\mathrm{K} 2=1.63, \mathrm{df}=8, \mathrm{P}=0.99)$. The model predicted $60-80 \%$ of the variance of the outcome based on Cox \& Snell and Nagelkerke R square.

\section{Results}

A total of 61 patients with severe TBI who had undergone early DC were studied. Of these, $36(59 \%)$ patients were male and 25 (41\%) were female. Mean age of patients was $36.09 \pm 15.89$ years old (range: 1668 years). Of 61 patients, $33(54.1 \%)$ had favorable and $28(45.9 \%)$ had unfavorable outcome. Age more than 60 years was related to poor outcome. There was no significant relationship between patient's sex and outcome $(\mathrm{K} 2=0.062, \mathrm{P}=0.804)$. 
GCS in the patients before surgery were as follows: $11(18 \%)$ patients had initial GCS more than 8, while $27(44.3 \%)$ had GCS between 5-8 and 23 (37.3\%) had GCS less than 5 . Patients with critical head injury (GCS: 3-4) had the worst outcome at six months $(\mathrm{P}<0.001)$.

\section{The Pupils Appearance on Admission}

19(31.1\%) patients had midsize pupil, 16 $(26.2 \%)$ ones had pupil size less than normal (miosis), 14 (23\%) patients had unilateral mydriasis and $12(19.7 \%)$ patients had bilateral nonreactive mydriatic pupils. Patients with bilateral nonreactive mydriatic pupils had the worst outcome $(\mathrm{P}<0.001)$.

The midline shift in patients' initial CT scan was as follows:

$35(57.4 \%)$ patients had midline shift less than $10 \mathrm{~mm}$ and $26(42.6 \%)$ patients had midline shift more than $10 \mathrm{~mm}$ on CT scan. The odds ratio (OR) was estimated as 4.95 (confidence interval $(\mathrm{CI})=2.14-11.41$ ) indicating that patients with midline shift more than $10 \mathrm{~mm}$ were 6.15 times more likely to have risk of unfavorable outcome than those with midline shift less than $10 \mathrm{~mm}$ (Table 1).

As represented in table 2, GCS and age could predict the outcome of surgery significantly according to binary logistic regression test, so that higher age predicted unfavorable outcome with 1.13 times, and in $\mathrm{GCS}<5$ the probability of unfavorable outcome is about 192 times $(\mathrm{K} 2=1.63, \mathrm{df}=8$, $\mathrm{P}=0.99$ ).

According to chi-square test in this study, there is a significant relationship between the pupils size and midline shift more than $10 \mathrm{~mm}$ with unfavorable outcome of patients, but beside other variables such as age and GCS in binary logistic regression, this correlation was not significant.

\section{Discussion}

DC is a life-saving procedure which can decrease life-threatening refractory ICP and secondary brain damages [17].

According to the most trials on outcome in severe TBI, $47 \%$ of patients had favorable outcome (moderate disability or milder) $[15,16]$. In the literature, favorable outcome of patients with TBI who had undergone DC was reported to be ranged from less than $30 \%$ to more than $70 \%$ [34-37].
In a meta-analysis in 2009 on DC for TBI including 29 articles and 1,422 cases [33], authors reported the following sixmonth outcomes: $29 \%$ of patients died, $8 \%$ of patients were persistently vegetative, $16 \%$ of patients were severely disabled, $20 \%$ of patients were moderately disabled, and $27 \%$ of patients had mild or no disability. However, the outcome of these patients could be improved with time, for example according to Ho et al. study, about $25 \%$ of these patients who had an unfavorable outcome at six months had a favorable outcome after 18 months [38]. Perfect patient selection for DC would improve outcome in severe TBI [16-18].

Evidence from some studies indicates that the most important determinants of outcome of these patients are as follows: timing of the procedure, age of the patients, pupil size and reactivity, initial GCS of patients, comorbid conditions and initial CT scan findings [1823,29-32]. Patients who had undergone rapid operation had a significantly better outcome [18-20].

Lower GCS scores are associated with a poor outcome. Studies indicate that most of the mortalities were among patients with GCS of less than six at the time of craniectomy; whereas majority of the survivors had higher GCS scores (eight and above). Reddy et al. reported survival of $88 \%$ among their patients who had a preoperative GCS of eight and above, and survival of $27 \%$ among those with GCS less than eight $[11,14,15,20-23]$.

Age is another important factor which influences patient's outcome. Patients in younger age groups tend to have better outcome after surgery, and age greater than 50 years was associated with a poorer outcome. The incidence of complications was also higher above this age [19,23-25,39].

Clinical data show that nonreactive mydriatic pupils indicate a poor neurological outcome $[4,5]$.

The initial computed tomography findings i.e. diffuse cerebral edema, absence of basal cisterns and midline shift have been found to be correlated with poor outcome following DC. Preoperative midline shift more than 10 millimeter is believed to be a significant predictor of poor outcome $[5,26]$.

According to a study conducted 
Table 1. Outcome of Surgery based on Sex, GCS, Pupil size, and Midline Shift

\begin{tabular}{|c|c|c|c|c|c|c|}
\hline \multicolumn{3}{|c|}{ Variables } & $\begin{array}{c}\text { Favorable } \\
\mathbf{N}(\%)\end{array}$ & $\begin{array}{c}\text { Unfavorable } \\
\text { N (\%) }\end{array}$ & $\begin{array}{l}\text { Total } \\
\text { N (\%) }\end{array}$ & $\begin{array}{c}\text { Statistical } \\
\text { Test }\end{array}$ \\
\hline \multirow{2}{*}{ Sex } & & Male & $19(57.6)$ & $17(60.7)$ & $36(59)$ & \multirow{2}{*}{$\begin{array}{l}\mathrm{K}^{2}=0.062 \\
\mathrm{P}=0.804\end{array}$} \\
\hline & \multicolumn{2}{|r|}{ Female } & $14(42.4)$ & $11(39.3)$ & $25(41)$ & \\
\hline \multirow{3}{*}{\multicolumn{2}{|c|}{ GCS }} & $<5$ & $4(12.1)$ & $19(67.9)$ & $23(37.7)$ & \multirow{3}{*}{$\begin{array}{l}\mathrm{K}^{2}=21.56 \\
\mathrm{P}<0.001^{*}\end{array}$} \\
\hline & & $5-8$ & $20(60.6)$ & $7(25)$ & $27(44.3)$ & \\
\hline & & $>8$ & $9(27.3)$ & $2(7.1)$ & $11(18)$ & \\
\hline \multirow{4}{*}{\multicolumn{2}{|c|}{ Pupil Size }} & Midsize & $16(48.5)$ & $3(10.7)$ & $19(31.1)$ & \multirow{4}{*}{$\begin{array}{l}\mathrm{K}^{2}=35.38 \\
\mathrm{P}<0.001 *\end{array}$} \\
\hline & & Miosis & $13(39.4)$ & $3(10.7)$ & $16(26.2)$ & \\
\hline & & $\begin{array}{l}\text { Unilateral } \\
\text { Mydriasis }\end{array}$ & $4(12.1)$ & $10(35.7)$ & $14(23)$ & \\
\hline & & $\begin{array}{c}\text { Bilateral } \\
\text { Mydriasis }\end{array}$ & $0(0.0)$ & $12(42.9)$ & $12(19.7)$ & \\
\hline \multirow{2}{*}{\multicolumn{2}{|c|}{ Midline Shift }} & $<10 \mathrm{~mm}$ & $28(84.8)$ & $7(25)$ & $35(57.4)$ & \multirow{2}{*}{$\begin{array}{l}\mathrm{K}^{2}=22.18 \\
\mathrm{P}<0.001 *\end{array}$} \\
\hline & & $>10 \mathrm{~mm}$ & $5(15.2)$ & $21(75)$ & $26(42.6)$ & \\
\hline
\end{tabular}

: significant

Table 2. Logistic Regression Predicting Outcome by Age, Midline Shift, Pupil Size and GCS

\begin{tabular}{|c|c|c|c|c|}
\hline \multicolumn{2}{|c|}{ Predictor } & Significance & Odd Ratio & $\begin{array}{c}\mathbf{9 5 \%} \text { Confidence } \\
\text { Interval }\end{array}$ \\
\hline \multicolumn{2}{|c|}{ Age } & $0.015^{*}$ & 1.13 & $1.02-1.25$ \\
\hline \multicolumn{2}{|c|}{ Midline Shift } & 0.155 & 6.15 & $0.502-75.46$ \\
\hline \multirow{3}{*}{ Pupil Size } & Miosis & 0.844 & 1.26 & $0.124-12.81$ \\
\hline & $\begin{array}{l}\text { Unilateral } \\
\text { Mydriasis }\end{array}$ & 0.362 & 3.55 & $0.233-54.3$ \\
\hline & Bilateral Mydriasis & 0.998 & 1.038 & $0.134-13.21$ \\
\hline \multirow[t]{2}{*}{ GCS } & $<5$ & $0.028^{*}$ & 192.3 & $1.76-20.94$ \\
\hline & $5-8$ & 0.693 & 1.96 & $0.068-56.52$ \\
\hline
\end{tabular}

in 2010 by Patrick and colleagues in Nigeria, GCS more than eight, age less than 50 years, and early surgery were associated with better prognosis [12].

The present study is consistent with most studies. Accordingly, following factors are related with poor prognosis and significantly worse outcome:

age more than sixty years and GCS less than five. In this study, according to chisquare test, there is a significant relationship between the pupil size and midline shift more than $10 \mathrm{~mm}$ with unfavorable outcome of patients, but beside other variables such as age and GCS in binary logistic regression, this correlation was not significant.

Limitations: All of our patients could not refer to our clinic at six months, and we had to contact them or their caregiver by telephone to complete the questionnaires.
Other factors which can influence the patient outcome such as hypotension, hypoxia and so on were not assessed in this study.

\section{Conclusion}

Factors associated with poor outcome in patients undergoing DC in our study are as follows:

age more than sixty years and GCS less than five.

Patients with these conditions could not benefit from a rapid DC.

\section{Funding}

This research did not receive any specific grant from funding agencies in the public, commercial, or not-for-profit sectors.

\section{Conflicts of interest}

No potential conflicts of interest were disclosed. 
Authors' Contribution

Conception and Design: Alireza Abdi

Data Collection: Ehsan Alimohammadi

Drafting the Article: Omid Beiki

Critically Revising the Article: Seyed Reza

Bagheri, Ehsan Alimohammadi, Hamidreza

Saeidi

Reviewed Submitted Version of Manuscript: Reza Fatahian, Pezhman Soleimani, Parandoosh Sepehri

Approved the Final Version of the Manuscript: Ehsan Alimohammadi

\section{References}

1. Bratton SL, Chestnut RM, Ghajar J, et al. Guidelines for the man- agement of severe traumatic brain injury. VI. Indications for intracra- nial pressure monitoring. J Neurotrauma.;24 Suppl 1:S37-44. 2007.

2. Leif-Erik Bohman L Schuster J Decompressive Craniectomy for Management of Traumatic Brain Injury: An Update Curr Neurol Neurosci Rep 13:392, 2013.

3. Marshall LF, Smith RW, Shapiro HM. The outcome with aggressive treatment in severe head injuries. Part I: the significance of intracranial pressure monitoring. J Neurosurg. ;50(1):20-5. 1979.

4. Cooper DJ, Rosenfeld JV, Murray L, et al. Early decompressive craniectomy for patients with severe traumatic brain injury and refractory intracranial hypertension-a pilot randomized trial. J Crit Care.;23(3):387-93. 2008.

5. Schreckinger M, Marion DW. Contemporary management of trau- matic intracranial hypertension: is there a role for therapeutic hypo- thermia? Neurocrit Care.;11(3):427-36. 2009.

6. Eisenberg HM, Frankowski RF, Contant CF, Marshall LF, Walker MD. High-dose barbiturate control of elevated intracranial pressure in patients with severe head injury. J Neurosurg.;69(1):15-23. 1988.

7. Lazaridis C, Czosnyka M. Cerebral blood flow, brain tissue oxygen, and metabolic effects of decompressive craniectomy. Neurocrit Care. 16(3):478-84. 2012.

8. Ho CL, Wang CM, Lee KK, Ng I, Ang BT. Cerebral oxygenation, vascular reactivity, and neurochemistry following decompressive craniectomy for severe traumatic brain injury. J Neurosurg.;108(5):943-9. 2008.

9. Li LM, Kolias AG, Guilfoyle MR, Timofeev I, Corteen EA, Pickard JD, et al. Outcome following evacuation of acute subdural haematomas: a comparison of craniotomy with decompressive craniectomy. Acta Neurochir (Wien).;154(9):1555-61. 2012.

10. Weiner GM, Lacey MR, Mackenzie L, et al. Decompressive craniectomy for elevated intracranial pressure and its effect on the cumulative ischemic burden and therapeutic intensity levels after severe traumatic brain injury. Neurosurgery.66 (6):1111-8. 2010.

11.Bor-Seng-Shu E1, Figueiredo EG, Amorim RL, Teixeira MJ, Valbuza JS, de Oliveira MM, Panerai RB. Decompressive craniectomy: a meta-analysis of influences on intracranial pressure and cerebral perfusion pressure in the treatment of traumatic brain injury.J Neurosurg. Sep;117(3):589-96. 2012. 12. Patrick O. Eghwrudjakpor and Akaribari B Decompressive craniectomy following brain injury: factors important to patient outcome Libyan J Med, 5: 4620 , 2010.

13. Rubiano AM, Villarreal W, Hakim EJ, Aristizabal J, Hakim F, Diez JC, et al. Early decompressive craniectomy for neurotrauma: an institutional experience. Ulusal travma ve acil cerrahi dergisi= Turkish journal of trauma \& emergency surgery: TJTES. 2009 Jan;15(1):28.

14. Chen SH, Chen Y, Fang WK, Huang DW, Huang KC, Tseng SH. Comparison of craniotomy and decompressive craniectomy in severely head-injured patients with acute subdural hematoma. J Trauma.;71(6):1632-62011.

15. Syed A, Ahmad I, Hussain M, Al-Bya F, Solaiman A Outcome following decompressive craniectomy in severe head injury: Rashid Hospital experience Pan Arab Journal Of Neurosurgery Volume 13, No. 2, P:29-35, 2009.

16. Hutchinson PJ, Corteen E, Czosnyka M, et al. Decompressive craniectomy in traumatic brain injury: the randomized multicenter RESCUEicp study (www. RESCUEicp.com). Acta Neurochir Suppl;96:17-20, 2006. 17.Rengachary SS, Batnitzky S, Morantz RA, Arjunan K, Jeffries B. Hemicraniectomy for acute massive cerebral infarction. Neurosurgery; 8: 321_8. 1981.

$\mathrm{N}$ m

18. Aarabi B, Hesdorffer DC, Ahn ES, Aresco C, Scalea TM, Eisenberg HM. Outcome following decompressive craniectomy for malignant swelling due to severe head injury. J Neurosurg.;104(4):469-79. 2006.

19.Yang XF, Wen L, Shen F, et al. Surgical complications secondary to decompressive craniectomy in patients with a head injury: a series of 108 consecutive cases. ActaNeurochir.;150(12):1241-7, 2008.

20. Kjellberg RN, Prieto A. Bifrontal decompressive craniotomy for massive cerebral edema. J Neurosurg.;34(4):488-93. 1971.

21. Cooper DJ, Rosenfeld JV, Murray L, et al. Early decompressive craniectomy for patients with severe traumatic brain injury and refractory intracranial hypertension-a pilot randomized trial. J Crit Care.;23(3):387-93. 2008.

22. Schreckinger M, Marion DW. Contemporary management of traumatic intracranial hypertension: is there a role for therapeutic hypothermia? Neurocrit Care.;11(3):427-36. 2009.

23. Malmivaara K, Kivisaari R, Hernesniemi J, Siironen J. Cost effectiveness of decompressive craniectomy in traumatic brain injuries. Eur J Neurol.;18(4):656-62. 2011.

24. Stiefel MF, Heuer GG, Smith MJ, et al. Cerebral oxygenation following decompressive hemicraniectomy for the treatment of refractory intracranial hypertension. J Neurosurg.;101(2):241-7. 2004.

25. Stiver SI. Complications of decompressive craniectomy for traumatic braininjury. Neurosurg Focus.;26(6):E7. 2009. 26. Nalbach SV, Ropper AE, Dunn IF, Gormley WB. Craniectomy associated progressive extra-axial collections with treated hydrocephalus (CAPECTH): redefining a common complication of decompressive craniectomy. J ClinNeurosci.;19(9):1222-7. 2012.

27. Steyerberg EW, Mushkudiani N, Perel P, et al. Predicting outcome after traumatic brain injury: development and international validation of prognostic scores based on admission characteristics. PLoS Med ;5(8):e165. 2008.

28. Marshall LF, Marshall SB, Klauber MR, et al. The diagnosis of head injury requires a classification based on computedaxial tomography. JNeurotrauma. 1:S287-92.1992. 29. Roozenbeek B, Lingsma HF, Lecky FE, et al. Prediction of outcome after moderate and severe traumatic brain injury: external validation of the International Mission on Prognosis and Analysis of Clinical Trials (IMPACT) and Corticoid Randomisation After Significant Head Injury (CRASH) prognostic models. Criti Care Med.;40(5):1609-17. 2012.

30. Honeybul S, Ho KM, Lind CRP, Gillett GR. Decompressive craniectomy for diffuse cerebral swelling after trauma: long-term outcome and ethical considerations. J Trauma.;71(1):128-32. 2011.

31. Wen L, Wang H, Wang F, et al. A prospective study of early versus late craniectomy after traumatic brain injury. Brain Inj.;25(13-14):1318-24. 2011.

32. Albanèse J, Leone M, Alliez J-R, et al. Decompressive craniectomy for severe traumatic brain injury: evaluation of the effects at one year. Crit care Med.;31(10):2535-8. 2003. 33. Danish SF, Barone D, Lega BC, Stein SC. Quality of life after hemicraniectomy for traumatic brain injury in adults. A review of the literature. Neurosurg Focus.;26(6):E2. 2009. 
34. Kunze E, Meixensberger J, Janka M, Sörensen N, Roosen K. Decompressive craniectomy in patients with uncontrollable intracranial hypertension. Acta Neurochir Suppl.;71:16-8. 1998.

35. Meier U, Ahmadi S, Killeen T, Al-Zain FT, Lemcke J. Long-term outcomes following decompressive craniectomy for severe head injury. Acta Neurochir Suppl.;102:29-31. 2008.

36. Olivecrona M, Rodling-Wahlström M, Naredi $\mathrm{S}$, Koskinen L-OD. Effective ICP reduction by decompressive craniectomy in patients with severe traumatic brain injury treated by an ICP-targeted therapy. J Neurotrauma.;24(6):927-35. 2007.

37. Al-Jishi A, Saluja RS, Al-Jehani H, Lamoureux J. Primary or secondary decompressive craniectomy: different indication and outcome. Can J Neurol Sci.;38(4):612-20. 2011.

38. Ho KM, Honeybul S, Litton E. Delayed neurological recovery after decompressive craniectomy for severe nonpenetrating traumatic brain injury. Crit Care Med.;39(11):2495-500. 2011.

39. Bohman LE, Schuster JM. Decompressive craniectomy for management of traumatic brain injury: an update. Curr Neurol Neurosci Rep. 2013 Nov 1;13(11):392.

\section{Comments}

With much interest, I have read the article titled "Decompressive craniectomy in traumatic brain injury: factors influencing prognosis and outcome".

Decompressive craniectomy (DC) is usually the final option in treatment of intracranial hypertension. The surgical treatment for DC comprises 2 options; unilateral craniectomy for unilateral hemisphere swelling and large bilateral craniectomy for bilateral diffuse hemisphere swelling. The dominant hemisphere injury and pathologic process that cause swelling of hemisphere should be considered in assessment of outcome in surgical management. The indication for this procedure must be based on several diagnostic and clinical measures such as cranial CT scanning, TCD ultrasonography, ICP monitoring, and clinical signs. It seems that ICP monitoring may be useful in managing of TBI .

I think the best benefit of surgery will be observed in younger patients with reduction in ICP after decompression.

Other factors, such as timing of intervention, medical comorbidity of patients and rapid decline in ICP after decompression may affect outcome. Finally, carefull patient selection and early operation may improve functional outcome of surgical management of TBI.

Seyed Abolghasem Mortazavi, MD, Assistant Professor of Neurosurgery, Sina Hospital, Tehran University of Medical Sciences (TUMS) 